\title{
Ultra-Conductive Magnesium
}

\author{
Fran De Aquino ${ }^{1}$ \\ ${ }^{1}$ Professor Emeritus of Physics, Maranhao State University, UEMA, and Titular Researcher (R) of National \\ Institute for Space Research, INPE, Brazil \\ Correspondence: Fran De Aquino, Maranhao State University, UEMA, and Titular Researcher (R) of National \\ Institute for Space Research, INPE, Brazil. E-mail: deaquino@elointernet.com.br
}

Received: March 14, 2021

doi:10.5539/apr.v13n2p35
Accepted: April 3, 2021

Online Published: June 30, 2021

URL: http://dx.doi.org/10.5539/apr.v13n2p35

\begin{abstract}
The improvement of the electrical conductivity of usual metals is limited by the purity of the metal and the ability to grow single crystal structures. Also, it was observed that the AC conductivity of the metal increases when the frequency of the electrical current applied on the conductor increases. Here, we show that the pure Magnesium metal can exhibit an ultrahigh electrical conductivity when it is subjected to $360 \mathrm{~K}$ temperature, and an electrical current with frequency of the order of $1 \mathrm{GHz}$.
\end{abstract}

Keywords: ultra-conductivity, pure magnesium, $\mathrm{THz}$

\section{Introduction}

There is a search for conductors with ultrahigh electrical conductivity because they can lead to higher efficiency and less energy consumption in a wide range of applications.

By embedding graphene in metals $(\mathrm{Cu}, \mathrm{Al}$, and $\mathrm{Ag})$, it was recently obtained a maximum electrical conductivity three orders of magnitude higher than the highest on record (more than 3,000 times higher than that of $\mathrm{Cu}$, i.e., $\cong 10^{11} \mathrm{~S} / \mathrm{m}$ ) is obtained in such embedded graphene (Cao et al., 2019). The improvement of the electrical conductivity of usual conductors is basically limited by the purity of the metal. However, experimental studies show that the AC conductivity of some metals increase when the frequency of the electrical current applied on the metal increases (Kurien, Sebastian, Mathew, \& George, 2004). It is here shown that the pure Magnesium metal can exhibit an ultrahigh electrical conductivity when subjected to $360 \mathrm{~K}\left(87^{\circ} \mathrm{C}\right)$ temperature, and an electrical current with frequency of the order of $1 \mathrm{GHz}$. Why prioritize the Magnesium? First because, is relatively easy to obtain Magnesium highly pure (99.999\%). Second because, ultra-conductive Magnesium can be fundamental for the building of several novel devices, such as Gravitational Motors, Gravitational Thruster of Fluids, production of Microgravity environments, and a Cooling and Heating Gravitational System (De Aquino, 2021).

\section{Theory}

The AC electric conductivity is the electric conductivity originated from a potential dependent of time (For example, when AC current is applied on a conductor). The DC electric conductivity does not depend on the time; this conductivity is the well-known electrical conductivity that arises when a DC source is applied on the conductor. Thus, total electrical conductivity of a conductor is given by Kurien et al. (2014).

$$
\sigma_{\text {total }}=\sigma_{0}+\sigma_{\mathrm{AC}}
$$

where $\sigma_{0}$ is the part of the total conductivity which value is frequency-independent and temperature-dependent, it which arises from the drift mobility of electric charge carriers. So $\sigma_{0}$ is actually DC electrical conductivity; 
$\sigma_{\mathrm{AC}}$ is the part of the total conductivity which value is the frequency - and temperature - dependent, and is correlated to dielectric relaxation produced by localized electric charge carriers; usually $\sigma_{\mathrm{AC}}$ is expressed by

$$
\sigma_{\mathrm{AC}}=\sigma^{*}\left(\frac{\omega}{\omega_{0}}\right)^{\mathrm{s}}=\mathrm{k} \sigma_{\mathrm{DC}}\left(\frac{\omega}{\omega_{0}}\right)^{\mathrm{s}}=\sigma_{\mathrm{DC}}\left(\frac{\omega^{\mathrm{s}}}{\omega_{\mathrm{c}}^{\mathrm{s}}}\right)
$$

where $\sigma^{*}$ and $\mathrm{s}$ are composition - and temperature-dependent parameters; $0<\mathrm{s}<1$ (Kurien et al., 2014). $\mathrm{w}=2 \pi \mathrm{f} ; \omega_{\mathrm{c}}=2 \pi \mathrm{f}_{\mathrm{c}}$, where $\mathrm{f}_{\mathrm{c}}$ is a critical value to be determinated.

Substitution of Eq. (2) into Eq. (1) gives

$$
\sigma_{\text {total }}=\sigma_{\mathrm{DC}}\left(1+\frac{\mathrm{f}^{\mathrm{s}}}{\mathrm{f}_{\mathrm{c}}^{\mathrm{s}}}\right)
$$

Therefore, the total electrical conductivity of a conductor is directly proportional to the frequency $\mathrm{f}$ of the electrical current applied on the conductor (Smit \& Wijn, 1959).

In the particular case of $\mathrm{f}^{\mathrm{s}} / \mathrm{f}_{\mathrm{c}}^{\mathrm{s}} \gg>1$ Eq. (3) reduces to

$$
\sigma_{\text {total }} \cong\left(\mathrm{f} / \mathrm{f}_{\mathrm{c}}\right)^{\mathrm{s}} \sigma_{\mathrm{DC}}
$$

Experimental studies have revealed that below $10 \mathrm{GHz}$ the frequency as well as the temperature effect is negligible (Kurien et al., 2014) (this point to a value of the order of $10 \mathrm{GHz}$ for critical frequency $\mathrm{f}_{\mathrm{c}}$ at room temperature). At higher temperature, however, there is an increasing contribution resulting from ion mobility and crystal imperfection mobility. Also, at a higher temperature, conductivity effect becomes dominant. As the temperature increases, $\mathrm{AC}$ electrical conductivity increase due to increase in the drift mobility of thermally activated electrons (El Hiti, 1994), and reaches a maximum value at around $360 \mathrm{~K}\left(87^{\circ} \mathrm{C}\right)$, then decreases with temperature (Kurien et al., 2014). On the other hand, since Eq. (2) tells us that

$$
\omega_{\mathrm{c}}^{\mathrm{s}}=\frac{\omega_{0}^{\mathrm{s}}}{\mathrm{k}}=\frac{\left(2 \pi \mathrm{f}_{0}\right)^{\mathrm{s}}}{\mathrm{k}}=\left(2 \pi \mathrm{f}_{\mathrm{c}}\right)^{\mathrm{s}}
$$

where $\mathrm{k}=\sigma^{*} / \sigma_{\mathrm{DC}}$ (See Eq. 2). Then, Eq. (5) gives

$$
\mathrm{f}_{\mathrm{c}}^{\mathrm{s}}=\frac{\mathrm{f}_{0}^{\mathrm{s}}}{\mathrm{k}}=\mathrm{f}_{0}^{\mathrm{s}}\left(\frac{\sigma_{\mathrm{DC}}}{\sigma^{*}}\right)
$$

or

$$
f_{c}=f_{0}\left(\frac{\sigma_{D C}}{\sigma^{*}}\right)^{\frac{1}{s}}
$$

It is well-known that $\sigma^{*}$ is temperature -dependent, and that it increases much more with the increase of the temperature than $\sigma_{\mathrm{DC}}$ (Kurien et al., 2014). Then, assuming that

$$
\sigma_{\mathrm{DC}}=\sigma \mathrm{F}(\mathrm{T}) \approx \sigma \quad(\mathrm{F}(\mathrm{T}) \approx 1)
$$




$$
\sigma^{*}=\sigma F^{*}(T) \cong \sigma f_{0}^{s\left(\frac{T}{T_{C}}\right)}\left(F^{*}(T) \cong f_{0}^{s\left(\frac{T}{T_{C}}\right)}\right)
$$

where $\mathrm{F}(\mathrm{T})$ and $\mathrm{F}^{*}(\mathrm{~T})$ are, respectively, temperature-functions of $\sigma_{\mathrm{DC}}$ and $\sigma^{*}$, and $T_{C} \cong 360 K\left(87^{\circ} \mathrm{C}\right)$ is the critical temperature previously mentioned.

Substitution of Eq. (8) and Eq. (9) into Eq. (7) yields

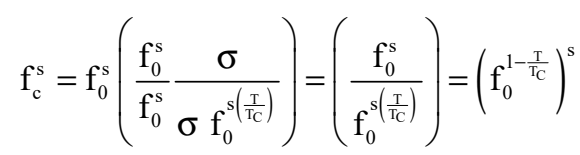

whence

$$
\mathrm{f}_{\mathrm{c}}=\mathrm{f}_{0}^{\left(1-\frac{\mathrm{T}}{\mathrm{T}_{\mathrm{C}}}\right)} \quad \mathrm{T} \leq \mathrm{T}_{\mathrm{C}}
$$

As we have seen, $f_{c} \cong 10 \mathrm{GHz}$ at room temperature $\left(T=25^{\circ} \mathrm{C}\right)$. Then assuming that $\mathrm{T}_{\mathrm{C}} \cong 87^{\circ} \mathrm{C}$, we obtain from Eq. (11):

$$
\mathrm{f}_{0} \cong 10^{14} \mathrm{~Hz}
$$

Therefore, according to Eq. (11), we have

$$
\begin{aligned}
& \text { For } \mathrm{T}=0^{\circ} \mathrm{C} \Rightarrow \mathrm{f}_{\mathrm{C}}=10^{14} \mathrm{~Hz} \\
& \text { For } \mathrm{T}=\frac{1}{4} \mathrm{~T}_{\mathrm{c}} \cong 21.7^{\circ} \mathrm{C} \Rightarrow \mathrm{f}_{\mathrm{C}}=31 \mathrm{GHz} \\
& \text { For } \mathrm{T}=\frac{1}{3} \mathrm{~T}_{\mathrm{c}} \cong 29^{\circ} \mathrm{C} \Rightarrow \mathrm{f}_{\mathrm{C}}=2.1 \mathrm{GHz} \\
& \text { For } \mathrm{T}=\frac{1}{2} \mathrm{~T}_{\mathrm{c}} \cong 43.5^{\circ} \mathrm{C} \Rightarrow \mathrm{f}_{\mathrm{C}}=10 \mathrm{MHz} \\
& \text { For } \mathrm{T}=\mathrm{T}_{\mathrm{c}} \cong 87^{\circ} \mathrm{C} \Rightarrow \mathrm{f}_{\mathrm{C}}=1 \mathrm{~Hz}
\end{aligned}
$$

Therefore, based on Eq. (11), we can conclude that $f_{c}$ strongly decreases with the increasing of the temperature $T$. At $T=T_{C}$ the value of the critical frequency $f_{c}$ should reach the maximum decrease, reducing down to a few $\mathrm{Hz}$ only. Under these conditions, for $\mathrm{f} \approx 1 \mathrm{GHz}$, the factor $\mathrm{f} / \mathrm{f}_{\mathrm{c}}$ (See Eq. 4) should reach a value of the order of $10^{9}$. Increasing therefore, the total electrical conductivity of the Magnesium for a value of the order of $10^{16} \mathrm{~S} / \mathrm{m}$, since the DC electrical conductivity of $\mathrm{Mg}$ is about $2.2 \times 10^{7} \mathrm{~S} / \mathrm{m}$. Note that the ultra-conductivity in this case is about $10^{5}$ times higher than the record of $\cong 10^{11} \mathrm{~S} / \mathrm{m}$, which it was obtained in the case of embedded graphene, mentioned in the introduction of this paper.

When Magnesium is in its metal form it will burn very easily in air. However, in order to start the reaction (the burning) the Magnesium metal needs a source of energy. The flame provides a source of heat so that the Magnesium metal atoms can overcome their activation energy. The ignition temperature of Magnesium is approximately $744 \mathrm{~K}\left(471^{\circ} \mathrm{C}\right)$. 
Glass ampoule (Magnesium in this ampoule with argon will remain shiny forever.)

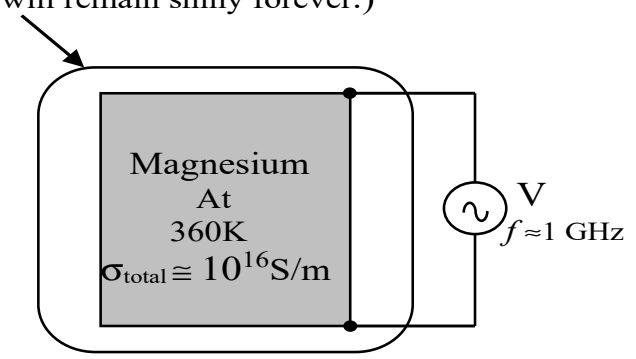

Figure 1. Ultra-conductive Magnesium - Magnesium metal 99.999\% pure should exhibits an electrical conductivity of the order of $10^{16} \mathrm{~S} / \mathrm{m}$ when subjected to $360 \mathrm{~K}$ temperature, and an electrical current with frequency of the order of $1 \mathrm{GHz}$.

\section{Conclusion}

Only experimental studies can determine with precision the value of $f_{c}$ at $360 \mathrm{~K}$. Thus, in conclusion, we suggest that experiments be carried out in order to verify the theoretical results here obtained.

\section{References}

Cao, M., Xiong, D. B., Yang, L., Li, S., Xie, Y., Guo, Q., ... \& Zhang, D. (2019). Ultrahigh electrical conductivity of graphene embedded in metals. Advanced Functional Materials, 29(17), 1806792.

Kurien, S., Sebastian, S., Mathew, J., \& George, K. C. (2004). Structural and electrical properties of nano-sized magnesium aluminate. Indian Journal of Pure \& Applied Physics, 42, 926-933.

De Aquino, F. (2021). Deceasing of gravitational mass of the magnesium subjected to an alternating magnetic field of extremely low frequency. Retrieved from https://hal.archives-ouvertes.fr/hal-03120208

Smit, J., \& Wijn, H. P. (1959). Ferrites. London: Clever-Hume Press.

El Hiti, M. A. (1994). DC conductivity for ZnxMg0. 8- xNi0. 2Fe2O4 ferrites. Journal of Magnetism and Magnetic Materials, 136(1-2), 138-142.

\section{Copyrights}

Copyright for this article is retained by the author(s), with first publication rights granted to the journal.

This is an open-access article distributed under the terms and conditions of the Creative Commons Attribution license (http://creativecommons.org/licenses/by/4.0/). 